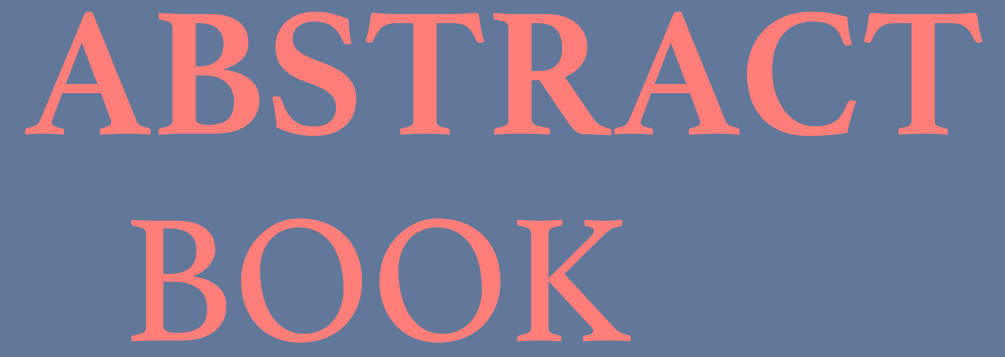

ISSN: $2547^{-8486}$

icSEP 20I9 International Conference on Sport, Education, and Psychology

02 - 03 May 2019

https://doi.org/10.15405/icsep2019(2547-8486) 
Future Academy ${ }^{\circledR}$

Abstract Book

$3^{\text {rd }}$ icSEP 2019 International Conference on Sport, Education and Psychology

02-03 May 2019/ Universitatea Spiru Haret, Bucharest, Romania

eISSN: $2547-8486$

The ISSN Cyprus Centre notifies that serial publication under the title icSEP 20I9 International Conference on Sport, Education, and Psychology has been allocated ISSN 2547-8486 and has been registered with the International Centre for the Registration of Serial publications, in Paris.

http://doi.org/IO.I5405/icsep2OI9(2547-8486)

All rights reserved.

Publisher $\Subset 2019$ Future Academy ${ }^{\circledast}$ Publishing Services

Editors () 2019 Bahire Akarturk

Individual contributions $\left({ }^{\circ} 2019\right.$ Their authors

This is an Open Access article distributed under the terms of the Creative Commons AttributionNoncommercial 4.0 Unported License, permitting all non-commercial use, distribution, and reproduction in any medium, provided the original work is properly cited. 


\section{icSEP 2019 \\ Abstract Book}

TABLE OF CONTENT 


\section{Table of Contents}

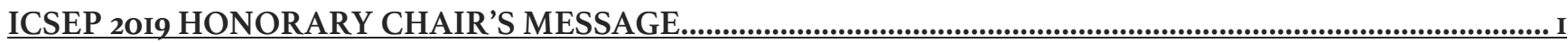

THE NOVICE PHYSICAL EDUCATION TEACHER AND SOLVING A GYM DISCIPLINE..............................2 VLADO BALABAN*, ŠTEFAN CHUDÝ, TEREZA BUCHTOVÁ. 2

THE RELATIONSHIP OF THE MENTAL STATE OF SPECIALISTS AND THEIR LEVEL DEVELOPMENT OF SELF-GOVERNMENT. . .3

L. ROGALEVA*, T. MARTYNOVA, L. BOYARSKAYA, V. SHTOKOLOK.. 3

EATING HABITS OF STUDENTS FROM A SPORTS HIGH SCHOOL IN SUCEAVA.. ADRIANA ALBU, MIHAELA CARAUSU, ARINA BADALUTA, FLORIN DIMA*. . .4

THE IMPORTANCE OF PHYSICAL ACTIVITIES IN MODERATING THE IMPULSIVENESS OF YOUNG GENERATION. 5

ELENA LUPU*

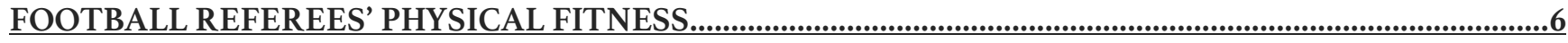
DAN MONEA, ELENA SABAU*, GEORGETA NICULESCU, ELENA LUPU 6

COACH-SPORTSPERSON PARTNERSHIP AND PROFESSIONAL ETHICS .7

IOANA LEPADATU*... 7

UNGUREANU-DOBRE AURORA*, DAIAN GLICHERIA, ALBINA CONSTANTIN, ALBINA ALINA, BRABIESCU CALINESCU LUMINITA . .8

EFFICIENCY OF COGNITIVE TRAINING IN PHYSICAL EDUCATION OF STUDENTS. . .9 ELENA LUPU*... . .9

MOTOR ACTIVITY FOR SPINAL DEFORMITIES IN CHILDREN OF PRE-SCHOOL AGE......................... IO RUSKA PASKALEVA*, VIOLETA IVANOVA, VANYA PAVLOVA ... IO 


\section{icSEP 2019 Honorary Chair's Message}

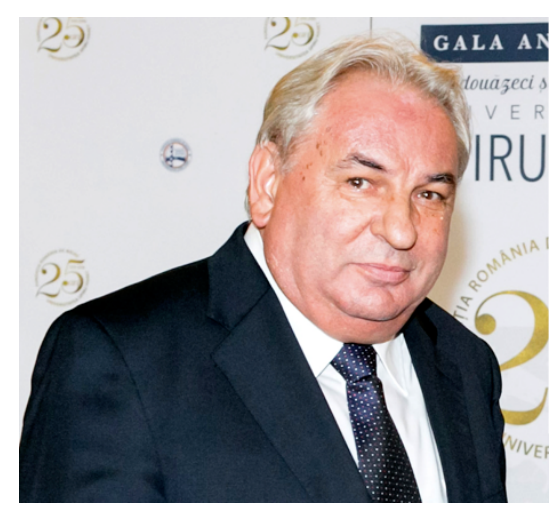

\section{Dear Colleagues,}

The International Conference on Sport, Education \& Psychology icSEP, 2019 organized by the Faculty of Physical Education and Sports - Spiru Haret University is a manifestation of friendship and professional relationships of the academic world.

We are honored to promote such an important and resourceful area, as education. The idea that should lead and inspire us all is to create and train a healthy in mind-and-body generation. And what else but sports is the best way to achieve this purpose.

The Conference is an excellent opportunity to disseminate the achievements of renowned researchers, professors, psychologists, students and, last but not least practitioners who work in the educational field, by means of their own specific methods.

We express our deepest appreciation to Dr. Zafer Bekirogullari for offering us this challenging event which is meant to help us promote education, psychology and sports in the entire academic world through the agency of the Future Academy.

May good luck and inspiration attend your entire work and publishing activity!

\section{Prof. Dr. Aurelian A. Bondrea}

Rector

Spiru Haret University - Universitatea Spiru Haret 


\title{
The Novice Physical Education Teacher And Solving A Gym Discipline
}

\author{
Vlado Balaban*, Štefan Chudý, Tereza Buchtová
}

"Institute of Education and Social Studies, Palacký University, Žižkovo nám. 5, 779 oo, Olomouc, Czech Republic

Problem Statement: Nearly $75 \%$ of novice teachers are faced with the problem of classroom discipline. With these problems are also faced and novice physical education teachers on as well. Research Questions: How novice physical education teachers solve breaking discipline during physical education class in the gym? Purpose of the Study: The main objective of this paper is to explore and analyse the phenomenon of breaking discipline during physical education lessons on the 2nd level of primary schools. The further aim is to analyse and describe the main problems which novice physical education teacher dealt. Findings: The most important findings are that novice physical education teacher is facing with many types of breaking disciplines in the gym. One of the reasons is also an emotional character of physical education as a school subject. Conclusions: Building authority is a very important element to abiding discipline during physical education lessons. Also, there is a wide group of tools for improving and maintaining discipline in the gym.

Keywords: Beginner teachers, Physical education, Classroom discipline. 


\title{
The Relationship Of The Mental State Of Specialists And Their Level Development Of Self-Government
}

\author{
L. Rogaleva*, T. Martynova, L. Boyarskaya, V. Shtokolok
}

"Ural Federal University, 620002, I9 Mira st., Ekaterinburg, Russia

The specialists 'activity in the field of sports (coaches, instructors, heads of the national teams and sport school directors) is connected with the high level of psycho-emotional stress which is determined by the raising of competition, extremely stressful atmosphere of the contests and intensive toll because of increasing the volume of training process of sportsmen. Based on this, it becomes relevant to study the role of those personal factors that can reduce mental capacity for work. The specialists of different age groups from 23 to 38 years, both the young specialists and professionals with experience of 8 -I5 years, took part in the experiment. As a result, it was found that the young professionals had higher rates of reduced efficiency in comparison with more experienced ones, due to the higher indexes of their mental satiety, fatigue and feeling of stress. At the same time, the level of self-government is significantly higher among specialists with experience due to such indicators as self-assessment, self-knowledge, self-development, selfcriticism, with equal indicators of self-realization scales. The studying of the relationship of mental states and indicators of self-government revealed an existing interrelation between the level of stress, satiety and the scales of self-assessment, self-criticism and self-development. The obtained data allow us to conclude that young professionals experience psycho-emotional overwork due to their unwillingness to make an objective assessment of their activity and its results, to assess their own capabilities adequately and focus on self-development.

Keywords: Mental state, self-government, specialists. 


\title{
Eating Habits Of Students From A Sports High School In Suceava
}

\author{
Adriana Albu, Mihaela Carausu, Arina Badaluta, Florin Dima*
}

*Gr. T. Popa University of Medicine and Pharmacy, Iasi

Nutrition is an external factor that contributes to the normal growth and development of the body and to good results in performance sports. Research questions are: (a) Do the students who are enrolled in a sports curriculum class have a more balanced diet compared to the students in a theoretical curriculum class? (b) Does the nutrition of students in the sports program correspond to rational nutrition guidelines?

Our goal is to find out the eating habits of students who practice performance sports. We will insist upon the imbalances that may appear. Comparative assessment using the two types of school programs allows for a better evaluation of the students' eating habits. The study was carried out on a group of I85 students from a Sports High School - 94 students from the sport profile (50.81\%) and 9I from the theoretical profile (49.18\%). The young people completed a weekly frequency questionnaire on food consumption and one related to the time allocated to sports every day. The processing of the results was done with the Pearson's chi-squared test. The time allotted to physical daily activity is in most cases over 90 minutes. Cheese is present in menus, especially once a week (39.45\%), meat preparations 2-3 times (35.13\%), potatoes 4-6 times per week (35.67\%), pasta 23 times or I time (34.59\%). There are cases of poor nutrition, especially with regard to animal products. In sports students, physical activity is intense, but it is not supported by adequate food intake. Nutritional intervention is required by a nutritionist specialized in sports.

Keywords: Sports, balanced nutrition, health. 


\title{
The Importance Of Physical Activities In Moderating The Impulsiveness Of Young Generation
}

\author{
Elena Lupu*
}

*Petroleum-Gas University, Bucharest Bvd., no. 39, Ploieşti, Ioo52o Romania

Motricity is a means of education in close connection with the intellectual and the affective sides of individuals and conceals behind it an entire universe related to the manner in which each individual acts and thinks in different situations. Research Questions: Should impulsiveness be analyzed every time in the context of other variables of individuality or in a singular context? The present research was undertaken on a group composed of: Experiment Group (E.G.), consisting of 47 students; - and a Control Group (C.G.) consisting of 57 students. The group was randomly chosen and, at least theoretically, the selected students had the same intellectual and physical potential. The research methods used were: the bibliographic study method, the observation method, the investigation method (conversation, the questionnaire "How impulsive are you?" etc.); the method of pedagogical experiment; the statistical-mathematical method; the graphic method. The purpose of the research was to verify the importance and role of physical activities in moderating the impulsiveness of the young generation. In conclusion, physical activities should be present at least once a week in the shedule of the young generation, being one of the few aspects that would influence the behaviour and diminish the instincts of aggressiveness and impulsiveness.

Keywords: Physical activities, students, basketball, impulsiveness. 


\title{
Football Referees' Physical Fitness
}

\section{Dan Monea, Elena Sabau*, Georgeta Niculescu, Elena Lupu}

\author{
"Spiru Haret University, 24, Berceni, Bucharest, Romania
}

Football is a team sport between two teams of II players each. The goal of the game is to score goals by placing a ball in the opponent's goal area. The football player must have a good physical condition. The most important abilities for a football player are: speed, coordination, strength, endurance. In the same time football players can deal very well with the ball. The football match is supervised by the referees. Referee effort in the game is similar to the football player without the ball. Football referees must develop according to the current demands in order to manage the modern-day game. They must have a good biological support and an optimal motor condition. The study purpose is to identify the football referees fitness level during the football game. Subjects of the practical study were 32 football Romanian referees League I, male 36 years old. All of them have different jobs and they deal with refereeing in their spare time. The research is based on specialist literature. We used some investigations, as: BMI, 4X40m test, Yo-yo intermittent test level I. The referees were tested two times at six months. Data were statistical processing, by basic parameters (average, median, standard deviation, amplitude, and homogeneity) and special parameters (test of normality - Kolmogorov-Smirnov and Shapiro-Wilk; test of significance of the difference - $t$ bilateral depend test. The results of the study highlight for the four tests: there are significant statistical differences between initial and final tests. In this circumstance the working hypothesis is accepted.

Keywords: Football, referee, sprint, endurance, fitness. 


\section{Coach-Sportsperson Partnership And Professional Ethics}

Ioana Lepadatu*

"Spiru Haret University, Faculty of Psychology and Education Sciences, Brasov, Romania

The purpose of the present study was to eliminate the malpractice from the sportspeople's training in team sports and to establish the meanings of the relationships between sportspeople-trainer and sportspeople - coach. Sometimes, the goals set by the trainer can lead to unfavorable consequences in the sportspeople's becoming. Under what conditions do these consequences occur and with what effects? From the perspective of professional relationships, are there differences between the sportspeople-trainer and the sportspeople-coach relationships? If so, what are they? Through observation, interview and evaluation of the products of the activity, the thesis is supported by a presentation of cases that, without falling into the malpractice of the sportspeople's training, illustrate the neglect of some complex aspects which sometimes may lead to favorable results on short term, but, on long term, they have unfavorable consequences on the sportspeople's becoming. A sportsperson's training to become a leader has minimized the contribution of the entire team. The respective trainer has achieved the goal of creating a leader, but the team's performance has been low. The trainer-sportspeople relationships are subordinate, while the coach-sportspeople relationship is of equality, a partnership in which confidentiality falls within the requirement of professional ethics.

Keywords: Malpractice of sportspeople's training, trainer- sportspeople relationship, coachsportspeople relationship. 


\title{
Managing The Students' Effort Following The Application Of The Circuit-Female Soccer
}

\author{
Ungureanu-Dobre Aurora*, Daian Glicheria, Albina Constantin, Albina \\ Alina, Brabiescu Calinescu Luminita
}

*University of Craiova, Brestei Street, No. 391, Craiova, Romania

During the preparatory period, before starting the training of the athletes, it would be necessary to understand their effort capacity in order to adequately conduct the effort, all this in view to ensure a superior functional capacity of their body by obtaining optimal values of the somatic and functional indices. Following the circuit application by components of the representative football team of the University of Craiova (ages between 20-24 years) and the recording of their heart rate, it is mandatory to redirect the effort for the adaptation of the body to effort. The Circuit - a methodical device which develops strength in resistance condition, contributing to the development of cardio-respiratory function. Following the interpretation of the heart rate values which were recorded after each station, after twice applying a circuit of seven stations with different duration and also different intensity, it was necessary to redirect the effort by eliminating one station and also increasing the gap between the two circuits from 3 to 4 minutes, due to the high heart rate. The heart rate values recorded in the initial test (February 20I7) assessed new effort management measures, also the heart rate values which were subsequently recorded from the final test (March 2017), confirmed the hypothesis we formulated and a good adaptation to the students body's effort.

Keywords: Heart rate, dynamic, stations, volume, power. 


\section{Efficiency Of Cognitive Training In Physical Education Of Students}

\section{Elena Lupu*}

"Petroleum-Gas University, Bucharest Bvd., no. 39, Ploiești, Ioo52o Romania

Cognition refers to a process of comprehension, gathering of information, expressed in the accumulated experiences present in every action of man. Research Questions: Would the introduction of a platform with theoretical notions for all students improve their attitude towards motion? Does the interest in motion increase if they have access to specific information? This research has started from the hypothesis that in the absence of awareness, motion performance and interest in motion would diminish by introducing theoretical notions of motion, in addition to the practical ones in the students' study program on an on-line platform, would make the result of motion performance to change positively and interest in motion to grow. As a result, the theoretical (cognitive) notions of practical activities would play a decisive role in triggering students' interest in physical education and increasing their motor performance. In conclusion, the introduction of theoretical notions about the benefits of motion on the on-line platform accessed by the interest and needs of the students would change their attitude towards the movement, which is proven by the improvement of motor performance.

Keywords: Physical education, students, cognition, motor performance. 


\title{
Motor Activity For Spinal Deformities In Children Of Pre- School Age
}

\author{
Ruska Paskaleva*, Violeta Ivanova, Vanya Pavlova
}

"Trakia University, Medical Faculty - Stara Zagora, Bulgaria

Motor activity for children with vertebral distortions is a major factor in general strengthening, proper development and stimulation of the whole organism. This helps to overcome spinal problems, improve the function of the lungs and the chest and create a strong muscle corset. The aim of the present study is to diagnose spinal deformities and to extend the professional competences of the students of specialty "Medical rehabilitation and ergotherapy" for work with children. The subject of the study is 248 children aged 6 and 7 from the kindergartens on the territory of the town of Stara Zagora during the clinical practice of the students. The analysis of the most common types of spinal deformities was the basis for compiling and conducting a program to increase the motor activity of children. Through a motor activity, swimming and sports games, the tone of the spinal muscles is improved, the muscle imbalance is overcome and the movement of the chest is stimulated. A healthy muscular corset is created and the neuropsychological development of the children is stimulated. Involvement of students in preventive actions to combat vertebral distortions is an innovative approach to practical training that stimulates motivation and improves practical skills.

Keywords: Motor activity, early diagnostics, spinal deformities. 


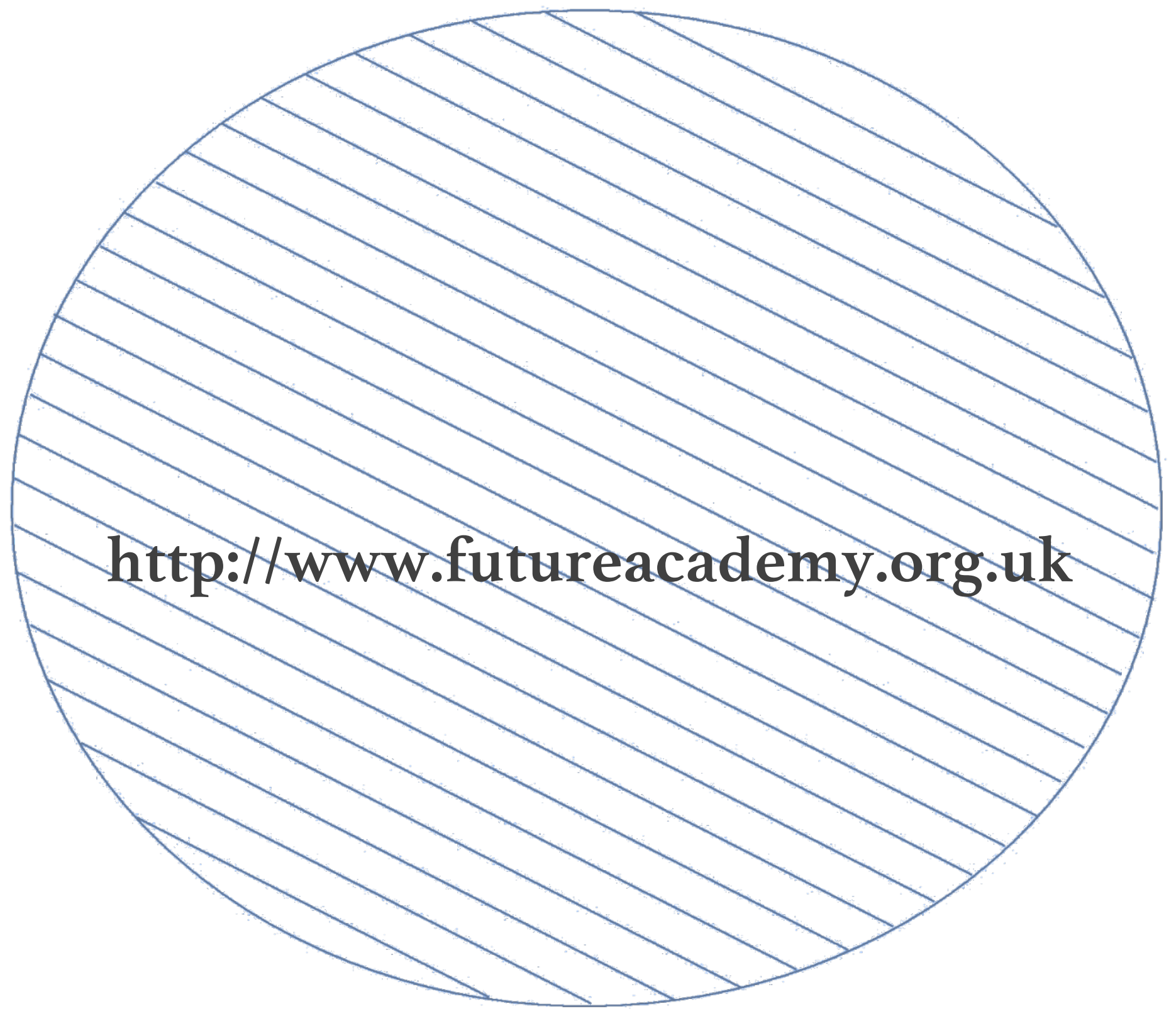

